\title{
Development of Heating Table Fabrication Process for the High Speed Curing Composites
}

\author{
Yun-hae Kim ${ }^{1}$, Jin-Cheol Ha ${ }^{1}$, Jin-Woo Lee ${ }^{1}$, Jun-Mu Park ${ }^{1}$, \\ Joong-Won Han ${ }^{2}$, Byung-Keun Choi ${ }^{2}$, Kyung-man Moon ${ }^{1}$ and Hironobu Nisitani ${ }^{3}$ \\ ${ }^{1}$ Department of Marine Equipment Engineering, Korea Maritime University, 1, Dongsam-dong, Youngdo-gu, Busan, 606-791, \\ Korea \\ ${ }^{2}$ Jet Korea Co. Ltd., Chang-won, Korea \\ ${ }^{3}$ Kyushu University, Hakozaki, Higashi, Fukuoka, Japan
}

(Manuscript Received December 20 2012; Revised January 11, 2013; Accepted February 14, 2013)

\begin{abstract}
Wind turbine generator is, recently, becoming bigger and bigger. So, in order to produce large amounts of electricity generation, we have to consider the length and thickness of the blade. We investigated the skills of processing for making the super thickness laminate through development fabrication process for high speed curing composite heating table.
\end{abstract}

Keywords: Composite material, Epoxy resin, Polyester resin, Wind turbine blade, Heating table.

\section{Introduction}

Composite materials show superior mechanical properties by combining of two or more separate materials. The most general form is that Matrix material is combined with reinforcement material of the fiber form. However, despite of that the resin itself which is used as matrix such as epoxy or polyester, etc. has the advantages of excellent corrosion resistance and formability, their utilization is very low because they have very weak mechanical strength compared to other material for structure. In contrast, glass fiber or carbon fiber used as reinforced material has excellent tensile and compressive strength, but its use is limited due to the disadvantage of the fragility in the solid state. The material which pursues excellent mechanical property and formability and corrosion resistance combining these materials is just a composite material.

Mechanical and chemical characteristics are deter-

${ }^{*}$ Corresponding author. Tel.: +82-51-410-4352, Fax.: +82-51-410-4350,

E-mail address: lab@hhu.ac.kr

Copyright $\odot$ KSOE 2013. mined depending on the nature of the resin and fiber reinforcement material, and if synthetically view, it can say that it is determined by factors such as Properties of Fiber, Properties of Resin, Fiber Volume Fraction, Geometry and Orientation of Fiber. Therefore, the composite material can be obtained lightweight, energy-absorbent, corrosion resistance, heat resistance, heat insulation, the freedom of product shape, the convenience of maintenance and the stability of product, etc.

\section{Wind Generator Blade}

The market competitiveness of wind industry according to the interest on renewable energy due to the rise in oil prices and the increase of revenue by electric generation, the improvement of wind turbine performance and the profit create of CERs (pollution credit), etc. is rapidly improving. The generating capacity of wind turbine is increased from few $\mathrm{kW}$ to dozens of $\mathrm{kW}$ for eighty years from 1900 to $1980 \mathrm{~s}$, and since 1980, the wind industry has been shown the tendency of the entry into commercialization and larger, and so it is the 
situation that its scale grows lager in about 120 times from $50 \mathrm{Kw}$ in the early 1980 's until $6 \mathrm{MW}$ in the end of 2009 due to accelerate the speed of development of the technology.

The structure of the wind turbine system can be divided into a wind generator structure and the control system to control the wind turbine, and the wind blades are the most distinctive elements as the scale is getting increasingly larger and larger. This is because the performance and lifetime of the entire system are determined by the performance of the blade. The blade of $3 \mathrm{MW}$ class has the length of $44 \mathrm{~m}$ and the weight of about 10 tons, and the blade of $6 \mathrm{MW}$ class is the large structure which is length reaches to $63 \mathrm{~m}$. The material of the blade according to the large structure is required the composite material of which specific rigid and specific strength are excellent, and also it is required the study on the molding condition according to the weight as well as the thickness. To achieve this, the features for resin, reinforcing fibers and composite material, respectively, and mutual understanding are required.

Figure 1 summarizes the attributes of the resin formulations needed in fiber reinforced wind turbine blade composites made by infusion processes. This figure is used as a guide for determining the suitability of various technologies, for example a toughening technology, for use in wind turbine blade applications.

\section{Flow Rate, Viscosity and Curing of Poly- mer Resin for Wind Blades}

Carbon fiber, glass fiber, Kevlar fiber, etc. are used as the reinforcement material and they are processed in various form. The used resins are the thermosetting resin such as epoxy, polyester, vinylester, etc. While maintaining the physical properties of the products, the rapid progression of the impregnation and curing speed of resin leads to the reduction of productivity costs. To achieve this, the conditions for the resin flow rate, the viscosity of resin and the resin curing between the fibers of reinforcement should be reviewed. The flow rate of resin is governed by Darcy`s law, which it is proportional to the permeability coefficient of the reinforcement material and the applied pressure gradient and it is in inverse proportion to the resin viscosity.

The viscosity is one of the important factors that affect the flow rate of resin. The rate that the internal fiber mat is impregnated with resin is in reverse proportio to the resin viscosity. In general, the thermosetting resin is synthesized by the reaction progressed as time passes after mixing the main material and hardening agent, and the resin viscosity with the flow resistance is also increased. The resin is assumed as Newtonian fluid because the resin flow is mostly occurred at the beginning of curing reaction. The viscosity can be approximated by following equation considering the hardening degree.

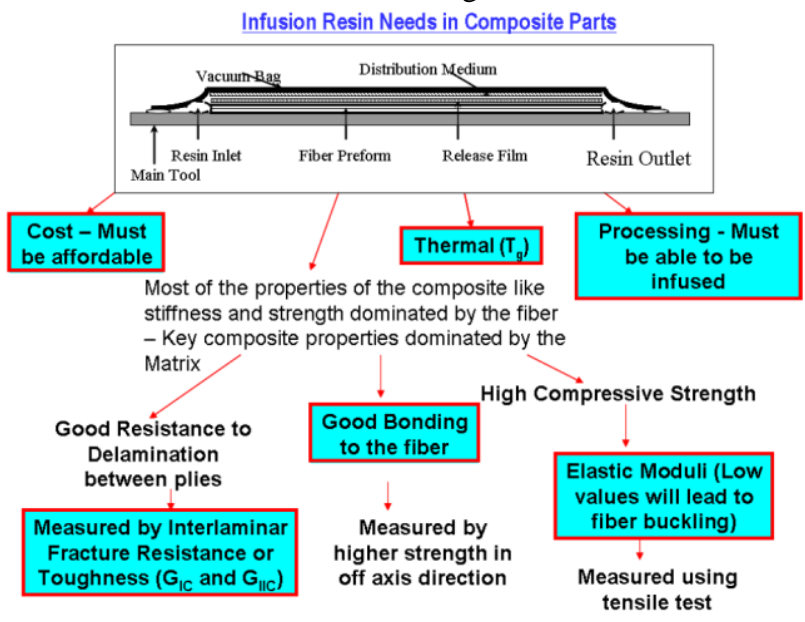

Figure 1. Summary of infusion resin needs in wind turbine blade composites. 


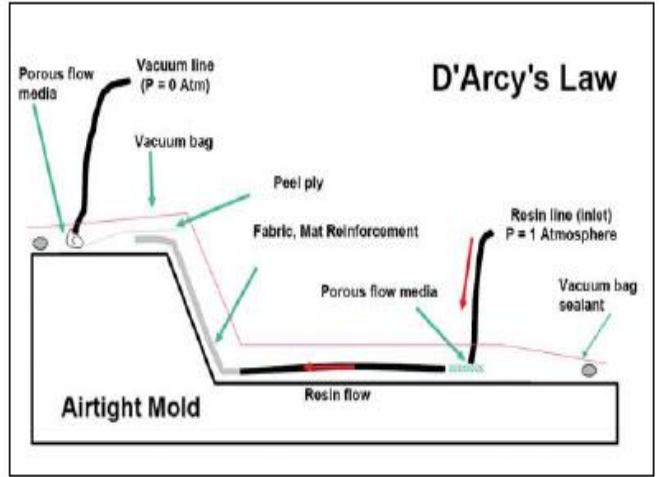

Fig.2 Darcy`s law and Infusion method

$$
\mu=\mu_{\infty} \exp \left(\frac{\Delta E}{R T}+k \alpha\right)
$$

$$
\begin{aligned}
& \mu_{\infty}, \mathrm{k}: \text { Viscosity }- \text { related constant } \\
& \qquad \Delta E: \text { Activation energy } \\
& \mathrm{R}: \text { General gas constant }
\end{aligned}
$$$$
\alpha \text { : Degree of curing }
$$

Resin radiates heat involving with the change of various properties (viscosity, dielectric permittivity, refractive index) during chemical reactions, where calories, dielectric permittivity and refractive index are the state variables that quantify the degree of resin chemical reaction. For the convenience of the measurement is the most common way to quantify the chemical reaction calories, and calorific value measured by DSC (differential scanning calorimeter) is the most widely used method. The concept to quantify the degree of chemical reaction is the hardened degree, and it can be represented as the value that the sum of the calorific value until a random curing moment is divided by the total calorific value that is generated by the reaction. The heating table such as article (2) was manufactured for this study, and the conditions of viscosity, etc. can be controlled by injecting the resin maintaining table at a constant temperature regardless surrounding temperature condition during progressing of the resin injection process, and the author intend to progress the study for the process that the products of excellent quality can be made because the curing

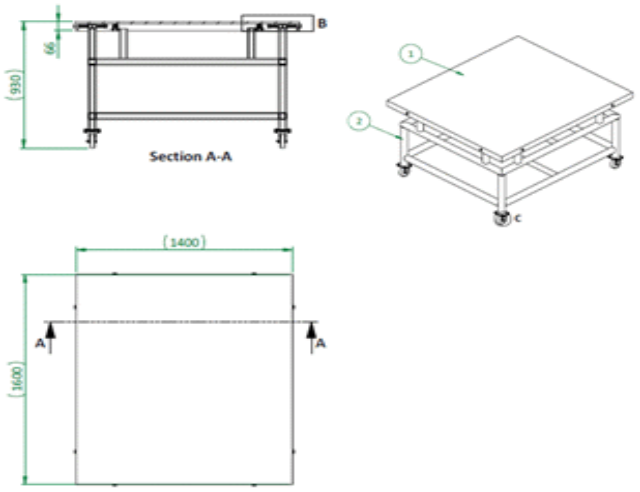

Fig.3 General drawing for heating table

can be controlled by elevating the temperature after that the resin injection is completed.

\section{Polymer Resin for Wind Turbine Blades}

Unsaturated polyester, vinyl-ester and epoxy are used as the base resin of the wind turbine composite blade. In the past, while lowering the weight of the blade as much as possible, the polyester resin was used considering production cost, but it is the trend that the wind blade in the wind turbine is converted to the epoxy resin composite material according to the requirements of lightweight, low shrinkage, excellent aging characteristics and high strength. Particularly, the resin for the lager blade shall be selected to fit in molding process of composite materials. In recent years, most of blades are manufactured by the resin injection process, and the resin system which various properties can be adjusted as the blades become larger is used. In the case of large blade, the resin of the optimal viscosity in the process is required because the flow distance is greatly increased in the resin injection process. Epoxy resin is typically made by polymerization of epichlorohydrine and bisphenol $\mathrm{A}$ as a unit of the chemical molecules composing it, and epoxy resin do not be used alone, and it is used as the thermosetting material changed by adding the hardener again. The characteristics of the epoxy resin are that the reaction shrinkage in curing is very small and volatile material do not occur. Also, electrical and mechanical properties are excellent and the product which machinability is good can be produced. In addition, it has high storage stability and if it don't mix the hardener, long-term storage is possible regardless of the climate or temperature. One of the 
advantages of epoxy resin is that it can be converted to thermosetting material, and this phenomenon is referred to the curing of epoxy resin. The hardener which is used in the curing is the easy material to react with the epoxy resin. In general, hardener has a different concept than catalyst, that is, catalyst cause the reaction but it does not exist as a part of the polymer by the direct reaction mixture, whereas hardener become directly a part of the reactants through the reaction. Because the curing reaction is exothermic reaction, heat is generated at the initiation of reaction. However, there are also the reactions that rely on heating. In general, if the reactants are heated, the time necessary to complete the curing reaction in proportional to the temperature of the heating can be shortened. When the curing temperature is too high, however, the properties of the hardened products tend to degrade.

So, it is important to select the appropriate temperature. Usually the high-purity epoxy resin is chemically very stable compound at less than $200^{\circ} \mathrm{C}$, and also it has thermoplastic properties. These properties allow the epoxy resin to compose a three-dimensional (net-shape) structure through the curing reaction. The curing reaction generally can be divided into three types through the studies that many people have been researched until now. There are firstly, the coupling reaction among the epoxy group, and secondly, the coupling reaction by the compounds with the hydroxyl group $(-\mathrm{OH})$ of the aliphatic or the aromatic series of epoxy group, and the cross-linking by the hardener of epoxy group, etc..

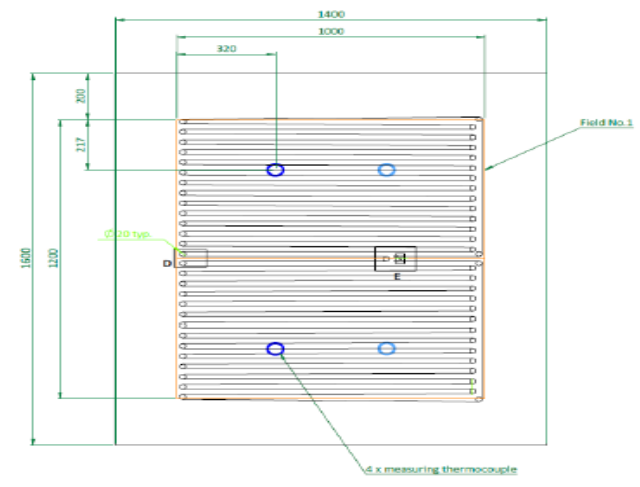

Fig.4 Heating line drawing
The typical characteristics that is required in resin injection process of the epoxy resin are as follows: the pot time (room temp./100g) needs more than 500min. and the viscosity (room temp.) should be less than $700 \mathrm{cps}$, and the curing condition should be maintained at $80^{\circ} \mathrm{C}$ for 100 hours or less, and the Reversed bending strength (DLR Brunsw) imust be exp.>1*106 (10\%), exp.>2*106 (10\%).

\section{Fiber for Wind Turbine Blades}

The reinforcing fiber is the most important element to determine the structural performance, and it occupies a part of more than about $40 \%$ of the entire volume and is the part receiving directly the external load. Usually carbon fiber and glass fiber are mainly used as the reinforcing fiber. Recently, the spar made of the carbon and glass fiber composite material is used in the blade system, but somewhat carbon fiber composite material should be used for larger blade. If carbon fiber is used for entire blade, however, the weight of blade can be reduced, but the price cause the problem and the stability of Reversed bending strength is the unproven state compared to glass fiber composite materials. If the thickness of parts become thinner due to the use of the carbon fiber composites, the thickness of it can increase in order to this phenomenon because the buckling can happen under low load.

The reinforced textile used for the composite blades depending on the lager blade is used NCF (multi-axis non-crip fabric) which the properties of fabric structure is excellent. This structure is applied in the large blade of more than $80 \%$.

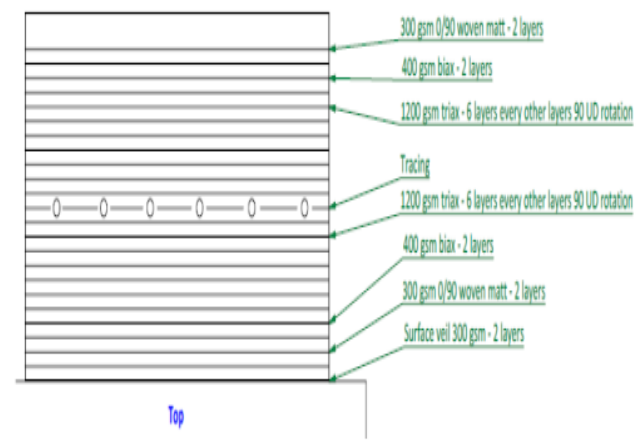

Fig.5 Heating field and Laminate built- up 


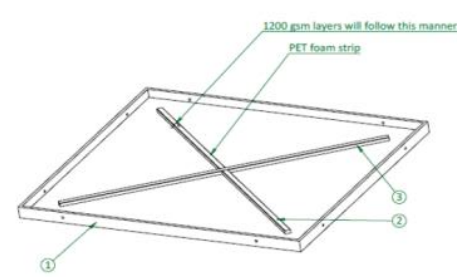

Fig.6 Laminated sheet for adiabatic materials Fig.7 Laminated sheet drawing
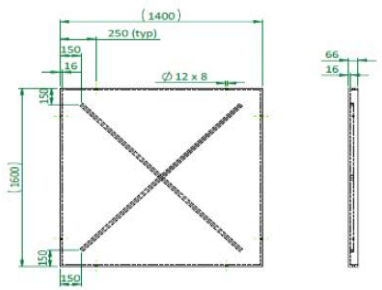

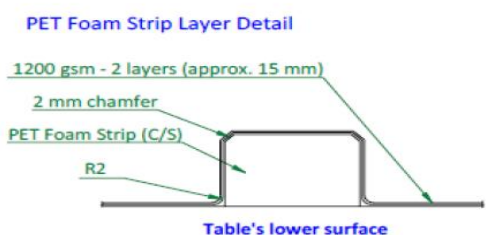

Fig.8 PET Foam Strip Layer Detail
In addition, it has suitable properties for the resin injection process. Curved fiber is minimized and the straightness of the fiber is greatly improved, and the productivity of the blade can be increased due to high fiber volume fraction.

\section{Manufacturing Process of Heating Table}

These are the schematic diagram and the detail drawings of the table.

To rise over $200^{\circ} \mathrm{C}$ the temperature in the resin impregnation, the bath should be insulated using Laminated sheet under the main plate as shown in Fig 5. Figure 6 and 7 are the detail drawing shown the size and PET foam strip layer.

\section{Conclusions}

The biggest reason to create the heating table is to improve the quality of the product, and the methods are to reduce the resin impregnation and the curing time depending on the increase of blade thickness by lager wind blades, and ultimately to find a new method to improve the quality of the product by the control of curing temperature. And this study has been conducted in the following order.

(1) lowering the viscosity of resin to give excellent liquidity

(2) shortening of the production time

(3) increasing of the properties

(4) extension of Gel time

The authors intend to ensure the technology to produce super thickness laminates by comparing suitable resin liquidity, temperature and time for the blade with maximum $120 \mathrm{~mm}$ thickness through further research.

\section{Acknowledgements}

This work (Grants No. S2046151) was supported by Business for Cooperative R\&D Institute funded Korea Small and Medium Business Administration in 2012. This work was financially supported by the Competitiveness Project for Professors at Korea Maritime University.

Following are results of a study on the "Leades INdustry-university Cooperation" Project, supported by the Ministry of Education, Science \& Technology (MEST).

\section{References}

[1] Y.H Kim, J.W Han, Composites Lecture (Hyosung publications, Korea 2001).

[2] B.S Hwang, An Understanding of Advanced Wind Turbines (A-Jin Publications, Korea 2009).

[3] BTM consult ApS“, International Wind Energy Development World Market Update 2007”, 2008.

[4] Dan Ancona and Jin McVeigh, "Wind TurbineMaterials and Manufacturing Fact Sheet,"Pinceton Energy Resources International LLC, 2001

[5] R. Shivpuri. E. Eruc,“ Planning and Simulation of the Ring Rolling Process for Improved Productivity", Int. J. Mach. Tools Manufact., Vol. 33, No.2, 1993, pp.153-173

[6] R. Bolin, "Ring Rolling”, ASM Handbook, Vol. 14A, Metalworking; Bulk Forming, ASM Int., Materials Park, OH 44073-0002 (2005), pp. 136-155

[7] Barry Berenberg“, Redesigning Wind Blades”, HIGH-PERFORMANCE Composites, 2002

[8] R. P. L. Nijssen, A. M. van Wingerade and D. R. V. van Delft,“ Wind Turbine Rotor Blade Materials: Estimating Service Lives”, SAMPE Journal, Vol. 43, No. 2, 2007

[9] Peter Meinlschmidt and Jochen Aderhold, "Defect Detection in Rotor Blades Using Thermo- 
graphic Inspection Techniques", FraunhoferInstitute for Wood Research, 2006

[10]IEC/TS 61400-23 : Full-scale structural testing of rotor blades, 2001-04

[11]E. Hau, WIND TURBINE, 2nd ed., Springer, Berlin Heidelberg, 2006

[12]B. Tony, S. David, J. Nick and B. Ervin“, Wind Energy Handbook", John \& Wiley Sons, 2001

[13]E. A. Bossanyi, GH Bladed Theory Manual, Garrad Hassan and Partners Ltd, 2005
[14]R. E. Wilson, and P. B. S. Lissaman, Applied Aerodynamics of Wind Power Machines, Oregon State University, 1974

[15]R. Thresher, S. Hock, R. Loose, and J. Cadogan, "The National Wind Technology Center", In Windpower" 94 Conference, Minneapolis, MN, May 9-13, 1994

[16]T. Burton, D. Sharpe, N. Jenkins, E. Bossanyi, WIND ENERGY HANDBOOK, John Wiley \& Son Ltd, 2001 